\title{
Implementation of an Emergency Department Sepsis Bundle and System Redesign: A Process Improvement Initiative
}

\author{
Tamara McColl, MD*; Mathieu Gatien, MD*; Lisa Calder, MSc, MD*; Krishan Yadav, MD*; \\ Ryan Tam, MD; Melody Ong, MD${ }^{\S}$; Monica Taljaard, $\mathrm{PhD}^{\dagger}$; Ian Stiell, MD, $\mathrm{MSc}^{*}$
}

\section{ABSTRACT}

Background: In 2008-2009, the Canadian Institute for Health Information reported over 30,000 cases of sepsis hospitalizations in Canada, an increase of almost 4,000 from 2005. Mortality rates from severe sepsis and septic shock continue to remain greater than $30 \%$ in Canada and are significantly higher than other critical conditions treated in the emergency department (ED). Our group formed a multidisciplinary sepsis committee, conducted an ED process of care analysis, and developed a quality improvement protocol. The objective of this study was to evaluate the effects of this sepsis management bundle on patient mortality.

Methods: This before and after study was conducted in two large Canadian tertiary care EDs and included adult patients with suspected severe infection that met at least two systemic inflammatory response syndrome (SIRS) criteria. We studied the implementation of a sepsis bundle including triage flagging, RN medical directive, education campaign, and a modified sepsis protocol. The primary outcomes were 30-day all-cause mortality and sepsis protocol use.

Results: We included a total of 167 and 185 patients in the pre- and post-intervention analysis, respectively. Compared to the pre-intervention group, mortality was significantly lower in the post-intervention group $(30.7 \%$ versus $17.3 \%$; absolute difference, $13.4 \%$; $95 \% \mathrm{Cl} 9.8-17.0 ; p=0.006)$. There was also a higher rate of sepsis protocol use in the postintervention group $(20.3 \%$ versus $80.5 \%$, absolute difference $60.2 \% ; 95 \% \mathrm{Cl} 55.1-65.3 ; p<0.001)$. Additionally, we found shorter time-intervals from triage to MD assessment, fluid resuscitation, and antibiotic administration as well as lower rates of vasopressor requirements and ICU admission.

Interpretation: The implementation of our multidisciplinary ED sepsis bundle, including improved early identification and protocolized medical care, was associated with improved time to achieve key therapeutic interventions and a reduction in 30-day mortality. Similar low-cost initiatives could be implemented in other EDs to potentially improve outcomes for this high-risk group of patients.

\section{RÉSUMÉ}

Contexte: En 2008-2009, I'Institut canadien d'information sur la santé a fait état de plus de 30000 hospitalisations pour de la sepsie au Canada, soit une augmentation de presque 4000 cas par rapport à 2005. Les taux de mortalité liés à une sepsie grave et au choc septique continuent à dépasser les $30 \%$ au Canada et ils sont passablement plus élevés que ceux liés à d'autres affections graves traitées au service des urgences (SU). Le groupe formé des auteurs a mis sur pied un comité pluridisciplinaire sur la sepsie, a réalisé une analyse du processus de soins au SU et a élaboré un protocole d'amélioration de la qualité. L'étude visait à évaluer les effets de cette marche à suivre (MS) dans la prise en charge (PC) de la sepsie sur la mortalité.

Méthode: Il s'agit d'une étude avant/après menée dans deux grands SU de soins tertiaires au Canada et portant sur des adultes qui étaient suspects d'une infection grave et qui respectaient au moins deux critères du syndrome de réaction inflammatoire généralisée. Les auteurs ont examiné la mise en œuvre d'une MS globale dans la PC de la sepsie, qui comprenait la façon de signaler les cas possibles de sepsie durant le triage, I'application de directives médicales par le personnel infirmier, une campagne de formation et l'application d'un protocole modifié de PC de la sepsie. Les principaux critères d'évaluation étaient la mortalité toutes causes confondues au bout de 30 jours et I'application du protocole de PC de la sepsie.

Résultats: Ont été inclus dans cette analyse avant et après intervention 167 et 185 patients, respectivement. Le taux de mortalité dans le groupe après l'intervention était significativement plus bas $(30,7 \%$ contre [c.] 17,3 \%; écart : $13,4 \%$; IC à $95 \%: 9,8-17,0 ; p=0,006$ ) que celui dans le groupe avant I'intervention. Le taux d'application du protocole de PC de la sepsie était également plus élevé dans le groupe après I'intervention (20,3\% c. 80,5\%; écart : $60,2 \%$; IC à $95 \%$ : 55 , $1-65,3 ; p<0,001)$ que dans le groupe avant I'intervention. En outre, les auteurs ont noté une diminution du temps écoulé depuis le triage jusqu'à l'évaluation des malades par les médecins, la restauration volémique et l'administration

From the ${ }^{*}$ Department of Emergency Medicine; ${ }^{\dagger}$ Ottawa Hospital Research Institute, University of Ottawa, Ottawa, ON; ${ }^{*}$ Department of Emergency Medicine, McGill University, Montreal, OC; and the ${ }^{\S}$ Department of Emergency Medicine, University of Manitoba, Winnipeg, MB.

Correspondence to: Tamara C. McColl, Department of Emergency Medicine, 1053 Carling Ave, F-Main, Room EM-206, Box 227, Ottawa, ON, K1Y 4E9; Email: tamaramccoll@gmail.com 
d'antibiotiques, ainsi qu'une diminution des taux d'administration de vasopresseurs et du nombre d'admissions au service de soins intensifs.

Interprétation: La mise en œuvre de cette MS globale et pluridisciplinaire dans la PC de la sepsie au SU, comprenant un repérage plus rapide des cas visés et l'application du protocole de soins médicaux, a été associée à une diminution du temps écoulé avant la réalisation d'interventions thérapeutiques importantes et à une diminution de la mortalité au bout de 30 jours. II serait possible de mettre en œuvre des initiatives similaires, peu coûteuses, dans d'autres $\mathrm{SU}$ et d'améliorer ainsi les résultats cliniques dans ce groupe particulier de patients à risque élevé.

Keywords: sepsis, severe sepsis, septic shock, sepsis bundle, quality improvement, emergency medicine, resuscitation

\section{INTRODUCTION}

As recently as 30 years ago, reported rates of in-hospital death from severe sepsis and septic shock were frequently greater than $80 \% .{ }^{1}$ Increased sepsis awareness, education, and the use of early goal-directed therapy have improved outcomes with emphasis on early recognition, fluid resuscitation, and antibiotic administration. ${ }^{2}$ The global burden, however, remains significant and the incidence of severe sepsis and septic shock is rising. ${ }^{3-5}$ A 2009 report published by the Canadian Institute for Health Information provided an alarming picture of an escalating number of cases of sepsis on a national level. ${ }^{6}$ In 2008-2009, they reported over 30,000 cases of sepsis hospitalizations in Canada, an increase by almost 4,000 from 2005. Mortality rates continue to remain greater than $30 \%$ in Canada and are significantly higher than other critical conditions treated in the emergency department (ED), including myocardial infarction, trauma, and stroke. ${ }^{7}$ The treatment of septic patients, therefore, must be approached with the same aggressive mindset used for other critical conditions, focusing on initiation of time-sensitive therapies in the early stages of disease presentation.

The high mortality rate associated with delayed diagnosis has resulted in an increase in sepsis-related research. ${ }^{8}$ Emphasis has been placed on early identification and treatment of septic patients using centerspecific protocols emulating guidelines set forth by the Surviving Sepsis Campaign. ${ }^{9}$ The recent publications of the ProCESS, ARISE, and ProMISe trials have underscored the importance of the fundamental elements in sepsis management: early recognition, fluid

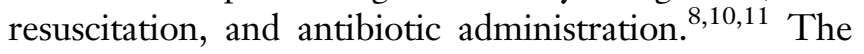
need for continued sepsis education, process improvement initiatives and protocolized ED care remains crucial as many sepsis cases still go unrecognized until the patient rapidly falls critically ill.

Based on the recommendations of the Surviving Sepsis Campaign and local expert opinion, Ottawa's two main tertiary care academic teaching hospitals implemented their own sepsis protocol in 2008, the Sepsis Treatment Early Protocol (STEP). ${ }^{13}$ An initial evaluation of this quality improvement protocol observed a substantial underutilization of the protocol and identified several deficiencies in our methods of identifying and managing septic patients. We therefore realized the need for a comprehensive quality improvement initiative. An interdisciplinary sepsis committee comprised of emergency physicians, nurses, intensivists, and infectious disease specialists was formed. Our main objectives were to enhance sepsis awareness among ED staff, promote early identification of septic patients, expedite management, improve sepsis protocol use, and ultimately reduce mortality in our septic patient population. The committee conducted an evaluation of our system processes and also assessed potential barriers to sepsis protocol implementation. This initial system-wide assessment led to the revision of our sepsis protocol, implementation of new sepsis triaging initiatives, $\mathrm{RN}$-initiated medical directive, and a focused education campaign. The overall aim of our study, therefore, was to evaluate the effect of our quality improvement sepsis management bundle on mortality and sepsis protocol compliance.

\section{METHODS}

\section{Design and setting}

We conducted a before and after study in two large tertiary care academic EDs at The Ottawa Hospital with a combined annual ED volume of over 130,000 patient visits. Patients were studied for a period of five months before (January-May 2013) and four months after (December 2013-March 2014) implementation of an enhanced sepsis protocol and ED system redesign. The post-intervention period was slightly shorter since we reached similar numbers after a four-month analysis. 


\section{Study population}

We included adult patients if they presented to the ED during the study period with suspected severe or serious infection and two or more of the following SIRS criteria based on the established STEP protocol: temperature greater than $38^{\circ} \mathrm{C}$ or less than $36^{\circ} \mathrm{C}$, heart rate greater than $90 \mathrm{bpm}$, respiratory rate greater than $20 \mathrm{rpm}$, or altered level of consciousness.

We excluded patients under the age of 18 years and patients with obvious minor infections who were expected to be discharged home from the ED. We also excluded patients who died within one hour of ED presentation.

Approval was obtained from the Ottawa Health Science Network Research Ethics Board.

\section{Study interventions}

Interventions were conducted in multiple phases (see Appendix Figure 1). First, we performed a process of care analysis to determine the current challenges with our sepsis protocol use. We subsequently developed a process map depicting each step in the patient's ED care, from triage all the way to final disposition and admission to hospital. Barriers to the identification and management of septic patients were determined at each step after collaborating with bedside and triage nurses, nurse managers, and educators. The information was then supplemented by a physician survey sent out to all emergency residents and staff physicians to ensure all avenues were considered.

Based on the information gathered, we implemented new triaging tools for potentially septic patients including a flagging system for the patient chart, protocolized ED destination from triage to a monitored bed, and a nurse-implemented medical directive in which fluid resuscitation and preliminary investigations are promptly initiated by the bedside nurse prior to physician assessment. Additionally, various physician prompts were instituted. Potentially septic patients were flagged directly from triage with a sepsis protocol attached to their charts as well as a sepsis toggle, in the form of a target sign, assigned to the patient on our electronic ED white board to alert the treating physician that the patient needs to be seen and managed in a timely fashion. Nurses were trained to verbally approach the attending physician to ensure they were aware of potential septic cases with the goal of initiating management within the first hour of patient arrival to the ED.
Next, we enhanced our existing sepsis protocol in accordance with the updated Surviving Sepsis Guidelines and local expert opinion as per our sepsis committee (see Appendix Figures 4-5). A systolic blood pressure threshold of less than $100 \mathrm{~mm} \mathrm{Hg}$ was added as an additional indicator to the inclusion criteria of the protocol. Lactate levels with repeated venous gases were also added along with more aggressive fluid resuscitation guidelines and updated specific antibiotic lists in accordance to the most probable site of infection and local resistance patterns. Additionally, dosages for two antibiotics, vancomycin and tobramycin, were adjusted based on weight, as we commonly under-dose our patients using a standard 70-kilogram model. We also included and emphasized reassessment after fluid resuscitation and provided a clear path to more aggressive interventions including vasopressors and stress-dose steroids for non-responders.

The last phase of our sepsis bundle intervention consisted of an extensive education campaign with the slogan "Target Sepsis", specifically targeting our emergency staff physicians, residents, and nurses, as well as ICU fellows and senior medical residents. This consisted of several departmental morbidity and mortality rounds, group presentations, luncheons, and visual aids in the department including posters, brochures and pocket cards. Branding our campaign with a Target Sepsis logo, consisting of a molecular bacterial model affixed on the background of a target sign, greatly aided our efforts and was a key factor in the success of our sepsis campaign.

\section{Data collection}

Data for study participants were collected from ED and hospital electronic records using a data collection tool in an Excel database. The same variables were collected in both the pre- and post-intervention phases of the study. We identified potential study cases by screening our hospital's electronic health records database with the following emergency discharge diagnostic search terms: sepsis, severe sepsis, septic shock, shock, bacteremia, septicemia, urosepsis, pneumosepsis, and meningitis. The cases that met these search terms were then individually assessed and charts were then either discarded or included in the study based on our pre-specified inclusion and exclusion criteria. Patientspecific variables were then entered into the database, which was secured via password to protect patient 
information. The variables assessed in this study were chosen by the investigators based on their clinical experience and reports in the literature.

Sixty cases were reviewed independently by two reviewers, 30 cases in the pre-intervention group and 30 cases in the post-intervention group. Data were collected for nine variables (meets criteria for protocol, protocol used, time to first fluid bolus (min), time to antibiotic administration (min), total fluids in first six hours (mL), ICU admission, final diagnosis, and 30-day mortality). There was agreement on all items aside from two disagreements regarding the amount of fluids administered. These two cases were discussed and it was determined that the discrepancy arose from inclusion of antibiotics as a source of fluid administration by the second reviewer in both cases.

\section{Outcome measures}

The primary outcomes were 30-day all-cause mortality and use of the sepsis protocol by ED physicians. Mortality was determined by analyzing patient health records and verifying information at both campuses of The Ottawa Hospital. All patients were accounted for by health records and none were lost to follow-up. Sepsis protocol use was similarly determined by reviewing patient health records and noting whether a sepsis protocol form was completed by the emergency physician.

Secondary outcomes included time from triage to physician assessment, time to intravenous fluids, time to antibiotic administration, lactate clearance, the use of vasopressor/inotropic medications, and ICU admission.

\section{Data analysis}

The association between the outcome measures and clinical variables were assessed by the appropriate univariate analyses according to the type of data: for nominal data, the chi-squared test with continuity correction; for ordinal variables, the Mann-Whitney $\mathrm{U}$ test; and, for continuous variables, the unpaired twotailed $t$-test, using pooled or separate variance estimates as appropriate.

Change from pre- to post-intervention in the primary outcomes and in dichotomous secondary outcomes was described using absolute risk difference together with 95\% confidence intervals (CI). Change in continuous outcomes with skewed distributions was described using medians and interquartile range and tested for statistical significance using Wilcoxon two-sample test.

We conducted secondary multivariable logistic regression analyses in order to confirm the findings of the primary analysis. We adjusted for the following potential confounders: age, chronic renal failure, dialysis, cardiac disease, smoking, normal chest $\mathrm{x}$-ray, systolic blood pressure, respiratory rate, temperature, CTAS triage level, urea level, and lactate level. These variables were selected because they were considered both biologically and statistically (on univariate analysis) to be associated with mortality.

To avoid loss of information due to exclusion of patients with missing values on at least one of the covariates, we conducted multiple imputation with 10 completed datasets. The Markov chain Monte Carlo (MCMC) method was used with a single chain for all imputations, 200 burn-in iterations before the first imputation and 100 iterations between imputations. ${ }^{12}$ The EM algorithm and a non-informative prior was used to compute starting values for the MCMC method. The imputation model included all potential confounders, the outcome, as well as several auxiliary variables. The logistic regression analysis was conducted separately for each of the 10 completed datasets and the results were combined using the rules of Rubin $^{13}$ to account for imputation uncertainty. Goodness of fit was examined using the Hosmer-Lemeshow test. To examine sensitivity of the results to the presence of missing data, we repeated the analyses using only patients with complete data. We would like to underscore, however, that no patients had missing data for either of the primary outcomes.

\section{RESULTS}

Figure 1 depicts the number of patients screened, excluded and enrolled in our study. We screened a total of 318 patient records in the pre-intervention phase of the study between January 2013 and May 2013 and 315 in the post-intervention phase between December 2013 and March 2014. After applying our inclusion and exclusion criteria, a total of 167 and 185 patients were enrolled in the pre- and postintervention analysis respectively. None were lost to follow-up.

The baseline demographic and clinical characteristics of patients in both groups are described in Table 1. Both groups are very similar aside from a higher percentage of 


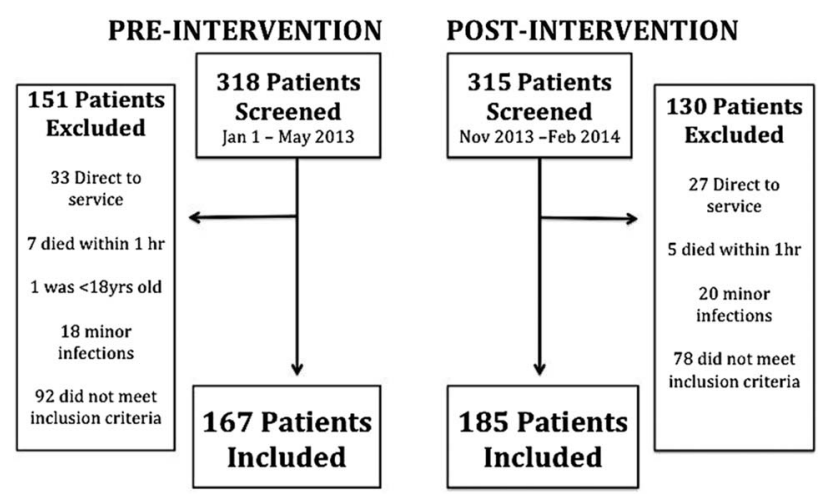

Figure 1. Flowchart of health record review process in the pre- and post-intervention phases.

patients with cardiac disease, smoking history, and active dialysis in the pre-intervention group.

Table 2 outlines the primary and secondary outcomes of septic patients in both phases of the study. The unadjusted all-cause mortality was significantly lower in the post-intervention group $(30.7 \%$ versus $17.3 \%$; absolute difference, $13.4 \%$; 95\% CI 9.8-17; $p=0.006$ ) (Appendix Figure 2). There was also a higher rate of sepsis protocol use in the post-intervention group (20.3\% versus $80.5 \%$, absolute difference $60.2 \%, 95 \%$ CI 55.1-65.3; $p<0.001$ ) (Appendix Figure 3). There was a notably shorter time-interval from triage to $\mathrm{MD}$ assessment, first fluid bolus, and antibiotic administration in the post-intervention group. Additionally, there was also a lower rate of vasopressor requirement and ICU admission in the post-intervention group. The percent improvement of serum lactate levels after six hours was much higher when the protocol was used both pre $(2.5 \%$ versus $23.3 \%)$ and post $(2.3 \%$ versus $29.3 \%)$ intervention. There was also a higher percentage of lactate clearance in the post-intervention group when the protocol was used (23.3\% versus $29.3 \%, p=0.05)$.

Table 3 demonstrates the unadjusted associations between mortality and clinical variables. As expected, there were significant associations with 30-day mortality for variables such as age, lower blood pressure, and altered level of consciousness. As with data published in previous studies, we found a relationship with mortality in patients with an initial lactate greater than four. Additionally, laboratory values demonstrating acidosis or renal insufficiency were also correlated with higher mortality rates. When considering past medical history, we found that cardiac disease, dementia, current dialysis, and recent steroid use also had an association with 30-day mortality.

\begin{tabular}{|c|c|c|}
\hline Characteristic & $\begin{array}{c}\text { Pre- } \\
\text { Intervention } \\
(\mathrm{N}=167)\end{array}$ & $\begin{array}{c}\text { Post- } \\
\text { Intervention } \\
(\mathrm{N}=185)\end{array}$ \\
\hline Age Years (Mean, SD) & $70.1(16.1)$ & $68.5(18.3)$ \\
\hline Male (\%) & $84(50.3)$ & $103(55.7)$ \\
\hline \multicolumn{3}{|l|}{ Treating Hospital (\%) } \\
\hline Ottawa Hospital Civic Campus & $81(48.5)$ & $86(46.5)$ \\
\hline $\begin{array}{l}\text { Ottawa Hospital General } \\
\text { Campus }\end{array}$ & $86(51.5)$ & 99 (53.5) \\
\hline \multicolumn{3}{|l|}{ Arrival Status(Mean, SD) } \\
\hline Heart Rate per minute & $110.7(23.5)$ & $112.8(21.0)$ \\
\hline $\begin{array}{l}\text { Systolic Blood Pressure in } \\
\mathrm{mmHg}\end{array}$ & $110.3(28.0)$ & $118.6(29.3)$ \\
\hline Respiratory Rate per minute & $24.2(7.2)$ & $23.2(5.9)$ \\
\hline Temperature degrees Celsius & $37.2(1.9)$ & $37.6(1.4)$ \\
\hline $\mathrm{SaO} 2$ by Oximetry (\%) & $94.2(5.1)$ & $94.5(8.6)$ \\
\hline Altered LOC $(\mathrm{GCS}<15)$ & $79(47.4)$ & $97(52.6)$ \\
\hline $\begin{array}{l}\text { Canadian Triage Acuity Scale } \\
\text { (CTAS) }\end{array}$ & $2.2(0.5)$ & $2.1(0.5)$ \\
\hline \multicolumn{3}{|l|}{ Departmental Triage (\%) } \\
\hline Resuscitation & $34(20.4)$ & $42(22.7)$ \\
\hline Emergent Care & $77(46.1)$ & $100(54.1)$ \\
\hline Observation & $50(29.9)$ & $37(20.0)$ \\
\hline Urgent Care & $6(3.6)$ & $2(1.1)$ \\
\hline \multicolumn{3}{|l|}{$\begin{array}{l}\text { Initial Laboratory Results } \\
\text { (Mean, SD) }\end{array}$} \\
\hline WBC & $15.9(10.8)$ & $15.4(14.8)$ \\
\hline $\mathrm{Hgb}$ & $121.3(22.3)$ & $120.5(24.2)$ \\
\hline Lactate (mmol/L) & 4.1 (3.4) & 3.9 (3.5) \\
\hline \multicolumn{3}{|l|}{ Past Medical History (\%) } \\
\hline Cardiac Disease & $82(49.1)$ & $67(36.2)$ \\
\hline Respiratory Disease & 56 (33.5) & $50(27.0)$ \\
\hline Cerebrovascular Event & $24(14.4)$ & $31(16.8)$ \\
\hline Diabetes Mellitus & 55 (32.9) & $51(27.5)$ \\
\hline Dementia & $30(18.0)$ & $30(16.1)$ \\
\hline Renal Insufficiency & $24(14.4)$ & 19 (12.4) \\
\hline Active Dialysis & $17(10.2)$ & $7(3.8)$ \\
\hline Active Cancer & $21(12.6)$ & 36 (19.5) \\
\hline Active Smoker & $28(16.8)$ & $16(8.6)$ \\
\hline Active Alcoholism & $10(6.0)$ & $10(5.3)$ \\
\hline HIV & $3(1.8)$ & $6(3.2)$ \\
\hline Organ Transplant & $4(2.4)$ & $2(1.1)$ \\
\hline Indwelling Device & $27(16.2)$ & $26(14.0)$ \\
\hline Recent Surgery (30 days) & $3(1.8)$ & $7(3.8)$ \\
\hline $\begin{array}{l}\text { Recent Hospitalization } \\
\text { (30 days) }\end{array}$ & $20(12.0)$ & $26(14.1)$ \\
\hline \multicolumn{3}{|l|}{ Current Medications (\%) } \\
\hline Oral Steroids in the last 30 days & $19(11.4)$ & 19 (10.3) \\
\hline Other Immunosuppressants & $3(1.8)$ & $10(5.4)$ \\
\hline Antibiotics & $42(25.1)$ & 45 (24.3) \\
\hline Current Chemotherapeutics & $9(5.4)$ & $15(8.1)$ \\
\hline Beta Blockers & 40 (23.9) & 36 (19.4) \\
\hline Home Oxygen & $11(6.6)$ & 7 (3.8) \\
\hline \multicolumn{3}{|l|}{ SIRS Criteria (\%) } \\
\hline Temperature greater than $38^{\circ} \mathrm{C}$ & $78(46.7)$ & $90(48.6)$ \\
\hline Temperature lower than $36^{\circ} \mathrm{C}$ & $47(28.1)$ & 47 (25.3) \\
\hline Heart rate greater than 90 bpm & $138(82.6)$ & $160(86.5)$ \\
\hline $\begin{array}{l}\text { Respiratory rate greater than } \\
20 \mathrm{rpm}\end{array}$ & $132(79.0)$ & $114(61.6)$ \\
\hline WBC greater than $12 \times 10^{9} / \mathrm{L}$ & $100(59.8)$ & $117(63.2)$ \\
\hline WBC less than $4 \times 10^{9} / \mathrm{L}$ & $15(8.9)$ & $12(6.5)$ \\
\hline
\end{tabular}

Table 4 shows the results from the multivariable logistic regression analysis. In total, 48 patients (13.6\%) had missing values on at least one covariate; however, 


\begin{tabular}{|c|c|c|c|c|c|}
\hline Outcome & $\begin{array}{l}\text { Pre-Intervention } \\
\qquad(\mathrm{N}=167)\end{array}$ & $\begin{array}{l}\text { Post-Intervention } \\
\qquad(\mathrm{N}=185)\end{array}$ & P-Value & $\begin{array}{l}\text { Absolute } \\
\text { Difference }\end{array}$ & $95 \% \mathrm{Cl}$ \\
\hline \multicolumn{6}{|l|}{ Primary Outcomes (\%) } \\
\hline All-Cause Mortality within 30 days & 30.7 & 17.3 & 0.006 & 13.4 & $9.8-17$ \\
\hline Protocol Use & 20.3 & 80.5 & $<0.001$ & 60.2 & $55.1-65.3$ \\
\hline \multicolumn{6}{|l|}{ Secondary Outcomes } \\
\hline $\begin{array}{l}\text { Time to MD Assessment } \\
\text { (Mean in min) }\end{array}$ & 74.4 & 59.3 & 0.010 & N/A & N/A \\
\hline Time to First Fluid Bolus (Mean in min) & 132.4 & 92.5 & 0.050 & N/A & $\mathrm{N} / \mathrm{A}$ \\
\hline $\begin{array}{l}\text { Total Amount of Fluids in First } 6 \text { hrs } \\
\text { (Mean in } \mathrm{mL} \text { ) }\end{array}$ & 2199 & 2357 & 0.220 & N/A & N/A \\
\hline $\begin{array}{l}\text { Time to Antibiotic Administration } \\
\text { (Mean in min) }\end{array}$ & 100.5 & 70.5 & $<0.001$ & N/A & N/A \\
\hline Use of Vasopressors in ED (\%) & 24.5 & 12.4 & 0.003 & N/A & N/A \\
\hline $\begin{array}{l}\text { Rate of ICU } \\
\text { Admission (\%) }\end{array}$ & 25.0 & 17.3 & 0.020 & N/A & N/A \\
\hline
\end{tabular}

there were no missing values for primary outcomes. The adjusted odds ratio comparing mortality in the post- versus pre-intervention periods was 0.51 (95\% CI $0.28-0.92$ ), which was significant with $p=0.026$. The C-statistic (area under the receiver operating characteristic curve) was 0.81 , and the Hosmer-Lemeshow $\chi 2$ goodness-of-fit statistic indicated adequate model fit $(p=0.563)$. The analyses using only patients with complete data were consistent with those conducted under multiple imputation.

\section{DISCUSSION}

\section{Interpretation of results}

Implementing the various components of our new sepsis management bundle, including triage flagging of potentially septic patients, fast-tracked monitored bed allocation, RN medical directive, an extensive sepsis education campaign, and a modified sepsis protocol, resulted in an expedited and more aggressive approach to sepsis management at our center.

We observed a dramatic increase in sepsis protocol use and a substantial decrease in mortality among septic patients. Additionally, time intervals from triage to the initiation of various management strategies, such as time to initial physician assessment, first fluid bolus, and antibiotic administration, were notably shorter in the post-intervention period. We also observed less vasopressor and inotrope use in the post-intervention group with an ensuing decrease in ICU admission.

\section{Previous studies}

Several studies have looked at the utility of sepsis protocolized care and have determined that the implementation of such protocols in the acute care setting results in decreased mortality. ${ }^{2,14-18}$ Our study was unique in that we not only looked at the intervention of implementing a sepsis protocol, but also looked at multiple changes in the process of care, including several new triaging tools, a nurse-activated medical directive, physician prompts, and an education campaign. Further strengths of our study included the minimal differences between our two study groups and a strong inter-observer agreement.

A recent large prospective randomized control trial, the ProCESS trial, received worldwide attention after the publication of controversial results regarding the utility of sepsis protocolized care after the authors found no differences in mortality between the three arms of the study; ED protocolized care, early goaldirected therapy (EGDT) mirrored after the River's trial, and usual ED physician bedside care. ${ }^{8}$ Similarly, the ARISE trial out of Australia conducted a large-scale randomized controlled study comparing outcomes in septic patients treated with EGDT versus usual ED care. ${ }^{10}$ They also found no significant difference in mortality rates between the two groups. Most recently, the ProMISe trial published equivalent conclusions. ${ }^{11}$ The general consensus reflected by the emergency medicine research community is that improved sepsis education, increased awareness, and the use of 
Table 3. Association between Mortality and Patient-Specific Variables

\begin{tabular}{|c|c|c|c|}
\hline Characteristic & Death within 30 Days $(\mathrm{N}=83)$ & Survival at 30 Days $(N=268$ ) & P-Value \\
\hline Male Gender (\%) & 48.2 & 54.5 & 0.31 \\
\hline Age (Mean) & 77.3 & 66.6 & $<0.001$ \\
\hline \multicolumn{4}{|l|}{ Arrival Status } \\
\hline Heart Rate $>90(\%)$ & 84.3 & 84.7 & 0.89 \\
\hline Respiratory Rate >20 (\%) & 77.1 & 67.5 & 0.09 \\
\hline Temperature $>38$ or $<36(\%)$ & 61.4 & 72.4 & 0.06 \\
\hline Altered LOC (GCS < 15) (\%) & 55.4 & 34.0 & $<0.001$ \\
\hline $\begin{array}{l}\text { O2 Saturation (>90\% on } \\
\text { Room air) (\%) }\end{array}$ & 39.8 & 58.6 & $<0.001$ \\
\hline SBP (Mean) & 106.4 & 118.1 & 0.001 \\
\hline \multicolumn{4}{|l|}{ Departmental Triage (\%) } \\
\hline Resuscitation & 33.7 & 17.9 & 0.02 \\
\hline Emergent Care & 44.6 & 51.7 & 0.27 \\
\hline Observation & 19.3 & 26.5 & 0.18 \\
\hline Urgent Care & 1.2 & 2.6 & 0.34 \\
\hline \multicolumn{4}{|l|}{ Initial Labs } \\
\hline$W B C>12$ or $<4(\%)$ & 71.1 & 65.3 & 0.32 \\
\hline Lactate $>4(\%)$ & 53.0 & 22.8 & $<0.001$ \\
\hline Lactate (Mean) & 5.5 & 3.5 & $<0.001$ \\
\hline Sodium (Mean) & 137.2 & 135.5 & 0.21 \\
\hline Potassium (Mean) & 4.6 & 4.2 & 0.14 \\
\hline Carbon Dioxide (Mean) & 22.1 & 24.5 & 0.01 \\
\hline Urea (BUN) (Mean) & 17.4 & 10.7 & $<0.001$ \\
\hline Creatinine (Mean) & 181.3 & 133.3 & 0.007 \\
\hline \multicolumn{4}{|l|}{ Past Medical History (\%) } \\
\hline Cardiac Disease & 53.0 & 35.1 & 0.004 \\
\hline Respiratory Disease & 30.1 & 30.2 & 0.99 \\
\hline Cerebrovascular Event & 19.3 & 14.6 & 0.30 \\
\hline Diabetes Mellitus & 26.5 & 30.6 & 0.48 \\
\hline Dementia & 27.7 & 12.7 & 0.001 \\
\hline Renal Insufficiency & 21.7 & 10.8 & 0.01 \\
\hline Active Dialysis & 12.0 & 5.2 & 0.03 \\
\hline Active Cancer & 19.3 & 15.3 & 0.39 \\
\hline Active Smoker & 10.8 & 13.1 & 0.59 \\
\hline Active Alcoholism & 3.6 & 5.6 & 0.47 \\
\hline HIV & 3.6 & 2.2 & 0.49 \\
\hline $\begin{array}{l}\text { Organ Transplant } \\
\text { Indwelling Device }\end{array}$ & 3.6 & 1.1 & 0.13 \\
\hline Recent Surgery (30 days) & 2.4 & 3.0 & 0.78 \\
\hline $\begin{array}{l}\text { Recent Hospitalization } \\
\text { (30 days) }\end{array}$ & 19.3 & 11.2 & 0.14 \\
\hline \multicolumn{4}{|l|}{ Medications (\%) } \\
\hline Steroids in the last 30 days & 16.7 & 9.0 & 0.04 \\
\hline Other Immunosuppressants & 2.4 & 4.1 & 0.48 \\
\hline Antibiotics & 25.3 & 24.6 & 0.90 \\
\hline Current Chemotherapeutics & 7.2 & 6.7 & 0.87 \\
\hline Beta Blockers & 24.1 & 18.7 & 0.28 \\
\hline Home Oxygen & 8.4 & 3.7 & 0.08 \\
\hline \multicolumn{4}{|l|}{ Chest X Ray (\%) } \\
\hline Clear & 28.9 & 50.4 & $<0.001$ \\
\hline \multicolumn{4}{|l|}{ Interventions (\%) } \\
\hline Protocol Used & 38.6 & 56.0 & 0.006 \\
\hline
\end{tabular}




\begin{tabular}{lccc|}
$\begin{array}{l}\text { Table 4. Estimated effect of intervention after adjusting for } \\
\text { potential confounders using } \\
\text { analysis }\end{array}$ & & & \\
\hline Variable & Odds Ratio & $95 \% \mathrm{Cl}$ & P-value \\
\hline Post- vs. Pre-intervention & 0.52 & $0.28-0.97$ & 0.0395 \\
Age & 1.04 & $1.02-1.07$ & 0.0002 \\
Chronic Renal Insufficiency & 1.67 & $0.72-3.88$ & 0.2333 \\
Smoker & 0.83 & $0.32-2.14$ & 0.7056 \\
Cardiac disease & 1.23 & $0.66-2.30$ & 0.5135 \\
Dialysis & 0.81 & $0.26-2.49$ & 0.7124 \\
Chest X-ray & 1.56 & $0.86-2.82$ & 0.1403 \\
Systolic Blood Pressure & 0.99 & $0.98-1.01$ & 0.3256 \\
Temperature & 0.84 & $0.70-1.02$ & 0.0809 \\
Urea & 1.03 & $1.00-1.05$ & 0.0549 \\
Lactate & 1.13 & $1.04-1.23$ & 0.0041 \\
Respiratory Rate & 1.05 & $1.01-1.10$ & 0.0260 \\
Triage CTAS & 0.64 & $0.34-1.19$ & 0.1577 \\
\hline
\end{tabular}

Area under the receiver operating characteristic $(R O C)$ curve $=0.81$

Hosmer-Lemeshow $\chi 2$ goodness-of-fit statistic, $p=0.5627$.

departmental sepsis protocols has created a new culture of enhanced general bedside ED management of septic patients and has subsequently decreased mortality when compared to rates in earlier studies. This solidifies the existing belief that ED sepsis protocols have significantly impacted the care and mortality outcomes of septic patients. Of particular importance is that both the ProCESS and ARISE trials demonstrate a substantial mortality decline from the initial River's EGDT study in 2001 to modern-day emergency care $(30.5 \%$ to approximately $18 \%-20 \%){ }^{8,10}$

\section{Limitations}

Several limitations of this study warrant mention. First, we employed a before-and-after study design, which invariably predisposes to the potential for sample selection bias, uneven baseline characteristics and the potential introduction of confounders. We attempted to minimize possible bias by including a consecutive sample in both arms of the study. As highlighted in Table 1, after analyzing patient characteristics, both groups were found to be fairly similar, however, it was not possible to account for all unmeasured differences between groups due to secular trends or due to a potentially more aggressive identification of patients in the post-intervention group. Given that we recruited the same number of patients in a shorter period of time in the post-implementation phase (four months versus five months), it is possible that we were more aggressively labelling patients with a diagnosis of sepsis in the post-intervention phase and potentially including patients who were less sick at baseline, even if those differences are not explicitly detected in measured baseline characteristics. We performed a multivariable analysis to control for potential differences in baseline characteristics and other confounders, which demonstrated an adequate model fit. Furthermore, we are not aware of any secular trends or new therapies that would have led to such a decrease in mortality within a oneyear period; however, it is not possible to fully exclude that possibility.

Second, we enrolled patients based on a pre-specified list of ED discharge diagnoses (see Methods). Although this list was fairly robust, it is certainly possible that we may have missed some septic cases that were given a generic discharge diagnosis (e.g., urinary tract infection as opposed to urosepsis). The distribution of such cases, however, would likely be similar in both groups.

Third, reviewers were not blinded to the study period, group assignments, or outcomes. This is unlikely to have introduced significant bias given that outcomes such as death and protocol use were clearly defined and not subject to reviewer interpretation. Furthermore, performance of an inter-observer analysis found very high agreement in outcome ascertainment.

Fourth, the post-intervention period is at risk of bias due to the Hawthorne effect. We employed a hospitalwide campaign prompting sepsis awareness and improved management. It is possible that the sepsis campaign and the knowledge that patient outcomes were being monitored could have altered staff behavior and ultimately affected patient outcomes. To test for this and to examine for the presence of any secular trends, we conducted an interrupted time series statistical analysis and showed that mortality rates were not significantly altered month-to-month in the pre- and post-intervention groups.

Lastly, it could be argued that perhaps the preintervention patient population had greater severity of illness since they had higher rates of cardiovascular disease, smoking history, and end-stage renal disease requiring dialysis. To further evaluate this theory, we conducted a multivariable analysis of our data and found that there was no significant difference in baseline characteristics affecting mortality between the pre- and post-intervention groups. 


\section{Clinical implications}

Our results underscore the importance of basic sepsis management principles: early recognition, early administration of antibiotics, and early volume resuscitation. At our center, we found that the implementation of a few basic process improvement strategies, such as a new triaging tool, nurse-initiated medical directive, physician prompts, updated protocol and sepsis education campaign, had a very high uptake in our ED, were associated with a substantial improvement in the management of our septic patient population and were associated with a substantial decline in mortality. These simple and low-cost interventions and results could likely be replicated in other EDs, whether in community or academic centers, and could potentially lead to improved sepsis care and ultimately improve patient outcomes on a larger scale.

\section{Research implications}

Our study yielded very promising results and encourages further research in the area of process improvement in the realm of sepsis management. An interesting extension of this study would be the implementation of a longitudinal education campaign and sepsis management surveillance initiative where emergency staff would receive real-time feedback on the care of their patients.

\section{CONCLUSIONS}

The implementation of our multidisciplinary ED sepsis bundle, including enhanced early identification and protocolized medical care, was associated with improved time to achieve key therapeutic interventions and a reduction in 30-day mortality. Similar low-cost initiatives could be implemented in other EDs and potentially improve outcomes for this high-risk group of patients.

Acknowledgements: The authors wish to thank the following individuals for their contributions to this study: Angela Marcantonio, Rina Marcantonio, My-Linh Tran, Cari Poulin, Dr. Rachel DeLong, and the Ottawa Sepsis Committee (Cari Poulin, Christine Beland, Ian Loney, Karen Moore, Dr. Rakesh Patel, Dr. Lisa Calder, Dr. Mathieu Gatien, Dr. Rachel DeLong, and Dr. Tamara McColl).

Competing Interests: None to declare

\section{SUPPLEMENTARY MATERIAL}

To view supplementary material for this article, please visit http://dx.doi.org/10.1017/cem.2016.351

\section{REFERENCES}

1. Friedman G, Silva E, Vincent JL. Has the mortality of septic shock changed with time. Crit Care Med 1998; 26(12):2078-86.

2. Rivers E, Nguyen B, Havstad S, et al. Early Goal-Directed Therapy Collaborative G. Early goal-directed therapy in the treatment of severe sepsis and septic shock. $N$ Engl 7 Med 2001;345(19):1368-77.

3. Linde-Zwirble WT, Angus DC. Severe sepsis epidemiology: Sampling, selection, and society. Crit care 2004;8(4): 222-26.

4. Alberti C, Brun-Buisson C, Burchardi H, et al. Epidemiology of sepsis and infection in icu patients from an international multicentre cohort study. IntensiveCare Med 2002; 28(2):108-21.

5. Levy MM, Artigas A, Phillips GS, et al. Outcomes of the surviving sepsis campaign in intensive care units in the USA and europe: A prospective cohort study. The Lancet Infect Dis 2012;12(12):919-24.

6. Husak L, Marcuzzi A, Herring J, et al. National analysis of sepsis hospitalizations and factors contributing to sepsis in-hospital mortality in Canada. Healthc Q 2010;13 Spec No:35-41.

7. Jawad I, Lukšić I, Rafnsson SB. Assessing available information on the burden of sepsis: Global estimates of incidence, prevalence and mortality. 7 Glob Health 2012; 2(1):010404.

8. ProCess Investigators; Yealy DM, Kellum JA, Huang DT, et al. A randomized trial of protocol-based care for early septic shock. $N$ Engl 7 Med 2014;370(18): 1683-93.

9. Dellinger RP, Levy MM, Rhodes A, et al. Surviving sepsis campaign: International guidelines for management of severe sepsis and septic shock: 2012. Crit Care Med 2013; 41(2):580-637.

10. ARISE Investigators; ANZICS Clinical Trials Group. Peake SL, Delaney A, Bailey M, et al. Goal-directed resuscitation for patients with early septic shock. $N$ Engl 7 Med 2014; 371(16):1496-506.

11. Mouncey PR, Osborn TM, Power GS, et al. Trial of early, goal-directed resuscitation for septic shock. $N$ Engl 7 Med 2015;372(14):1301-11.

12. Schafer JL. Analysis of Incomplete Multivariate Data. London/ New York: Chapman \& Hall; 1997.

13. Rubin DB. Multiple Imputation for Nonresponse in Surveys. New York; Wiley; 1987.

14. Micek ST, Roubinian N, Heuring T, et al. Before-after study of a standardized hospital order set for the management of septic shock. Crit Care Med 2006;34(11): 2707-13.

15. Castellanos-Ortega A, Suberviola B, Garcia-Astudillo LA, et al. Impact of the surviving sepsis campaign protocols 
on hospital length of stay and mortality in septic shock patients: Results of a three-year follow-up quasiexperimental study. Crit Care Med 2010;38(4):1036-43.

16. Nguyen HB, Kuan WS, Batech M, et al. Outcome effectiveness of the severe sepsis resuscitation bundle with addition of lactate clearance as a bundle item: A multinational evaluation. Crit Care 2011;15(5):R229.
17. Cannon CM, Holthaus CV, Zubrow MT, et al. The genesis project (generalized early sepsis intervention strategies): A multicenter quality improvement collaborative. 7 Intensive Care Med 2013;28(6):355-68.

18. Rivers EP, Katranji M, Jaehne KA, et al. Early interventions in severe sepsis and septic shock: A review of the evidence one decade later. Minerva Anestesiol 2012;78(6):712-24. 